\title{
Degradation of Biomaterials by Phagocyte-derived Oxidants
}

\author{
Kristin Sutherland, * John R. Mahoney II, * Arthur J. Coury, *s and John W. Eaton" \\ *Biomedical Engineering Program and ${ }^{\ddagger}$ Department of Surgery, University of Minnesota, Minneapolis, Minnesota 55455; ${ }^{\S}$ Medtronic \\ Inc., Minneapolis, Minnesota 55432; and "Division of Experimental Pathology, Albany Medical College, Albany, New York 12208
}

\begin{abstract}
Polymers used in implantable devices, although relatively unreactive, may degrade in vivo through unknown mechanisms. For example, polyetherurethane elastomers used as cardiac pacemaker lead insulation have developed surface defects after implantation. This phenomenon, termed "environmental stress cracking," requires intimate contact between polymer and host phagocytic cells, suggesting that phagocyte-generated oxidants might be involved. Indeed, brief exposure of polyetherurethane to activated human neutrophils, hypochlorous acid, or peroxynitrite produces modifications of the polymer similar to those found in vivo. Damage to the polymer appears to arise predominantly from oxidation of the urethane-aliphatic ester and aliphatic ether groups. There are substantial increases in the solid phase surface oxygen content of samples treated with hypochlorous acid, peroxynitrite or activated human neutrophils, resembling those observed in explanted polyetherurethane. Furthermore, both explanted and hypochlorous acid-treated polyetherurethane show marked reductions in polymer molecular weight. Interestingly, hypochlorous acid and peroxynitrite appear to attack polyetherurethane at different sites. Hypochlorous acid or activated neutrophils cause decreases in the urethane-aliphatic ester stretch peak relative to the aliphatic ether stretch peak (as determined by infrared spectroscopy) whereas peroxynitrite causes selective loss of the aliphatic ether. In vivo degradation may involve both hypohalous and nitric oxide-based oxidants because, after long-term implantation, both stretch peaks are diminished. These results suggest that in vivo destruction of implanted polyetherurethane involves attack by phagocyte-derived oxidants. (J. Clin. Invest. 1993. 92:2360-2367.) Key words: phagocytes $\bullet$ biomaterials $\bullet$ peroxynitrite $\bullet$ hypochlorous acid $\bullet$ oxidation
\end{abstract}

\section{Introduction}

Polyetherurethanes (PEU) ${ }^{1}$ have been important materials in implantable biomedical devices for more than two decades (1-

Address reprint requests to Dr. John W. Eaton, Division of Experimental Pathology, A-81, Albany Medical College, 47 New Scotland Avenue, Albany, NY 12208. The current address for Dr. Kristin Sutherland is St. Jude Medical, Inc., One Lillehei Plaza, St. Paul, MN 55117.

Received for publication 20 April 1993 and in revised form 14 June 1993.

1. Abbreviations used in this paper: ATR/FTIR, attenuated total reflectance Fourier transform infrared spectroscopy; EPO, eosinophil peroxidase; ESCA, electron spectroscopic chemical analysis; $\mathrm{HOCl}$, hy-

J. Clin. Invest.

(c) The American Society for Clinical Investigation, Inc.

$0021-9738 / 93 / 11 / 2360 / 08 \quad \$ 2.00$

Volume 92, November 1993, 2360-2367
$5)$. However, questions have been raised regarding the biostability of at least some forms of PEU (6-10). In one long-standing application, PEU has been used as insulation for cardiac pacemaker leads. In certain circumstances, surface crazing has occurred, progressing, in some cases, to deeper cracks and breach of the insulation. (It should be noted that these cracks occur only on the outside surface of the insulation. Additional lead degradation may arise from metal ion-induced oxidation [9].)

This process has been termed environmental stress cracking (11). This degradation of the material requires stress on the polymer, either from manufacture or from secondarily applied mechanical forces (12). One further critical factor appears to be host phagocytic cells. Large numbers of neutrophils (PMN) and macrophages tend to occupy the implant surface after short term implantations $(13,14)$, and if viable phagocytes cannot interact with implanted PEU, stress cracking does not occur (15). However, PEU cannot be significantly degraded by preformed products of phagocytic cells (such as cationic proteins and proteases) or by activated oxygen species such as superoxide and hydrogen peroxide (7). In view of the chemically stable nature of PEU, we hypothesized that the in vivo degradation of these materials might involve attack by chlorine-based and/or nitric oxide (NO ${ }^{\bullet}$ )-derived oxidants, major oxidative products of activated phagocytes. The results reported below support the idea that PMN-generated chlorine compounds are likely responsible for initial damage to PEU after brief implantation and that macrophage-derived $\mathrm{NO}^{\circ}$ and/or peroxynitrite $\left(\mathrm{ONOO}^{-}\right)$may further degrade $\mathrm{PEU}$ during long-term implantation.

\section{Methods}

Materials. Polyetherurethane Pellethane ${ }^{\otimes} 2363$ 80A pellets, injectionmolded PEU "dumbells" $(0.635 \mathrm{~cm}$ in length $)$, extruded PEU tubing, Teflon fixtures used to apply mechanical strain on the dumbells, and polysulfone mandrels were obtained from Medtronic, Inc. (Minneapolis, MN). The original supplier of PEU was Dow Chemical (Midland, MI). Unless otherwise noted, reagents and enzymes were purchased from Sigma Chemical Co. (St. Louis, MO). Sodium hypochlorite was obtained from EM Science (Gibbstown, NJ), and heparin came from Elkins-Sinn, Inc. (Cherry Hill, NJ). Dimethylformamide and $N$-methylpyrrolidone were obtained from Aldrich Chemical Co. (Milwaukee, WI); silicone-treated silk surgical sutures (4-0) from Davis and Geck, Inc. (Manati, Puerto Rico); Nembutal ${ }^{\oplus}$ sodium solution (pentobarbital sodium injection) from Abbott Laboratories (North Chicago, IL); $\mathrm{Ketalar}^{\circledR}$ (ketamine $\mathrm{HCl}$ injection, USP) from the Parke-Davis Division of Warner-Lambert Co. (Morris Plains, NJ); Percoll from Pharmacia Fine Chemicals (Piscataway, NJ); and Hetastarch (6\% solution

pochlorous acid; $\mathrm{Mn}$, average chain length in the polymer based on the number fraction; MPO, myeloperoxidase; Mw, average molecular weight; $\mathrm{NO}^{\circ}$, nitric oxide; $\mathrm{ONOO}^{-}$, peroxynitrite; $\mathrm{PB}$, phosphate buffer. 
in $\mathbf{0 . 9 \%}$ sodium chloride) from DuPont Pharmaceutical Corporation (Waukeegan, IL). Eosinophil peroxidase (EPO) was a gift from Dr. Arne Slungaard, University of Minnesota (Minneapolis, MN).

Preparation of materials and solutions. PEU samples strained to $400 \%$ elongation were prepared by first soaking PEU tubing (with an inner diameter of $\sim 0.178 \mathrm{~cm}$ and a wall thickness of $\sim 0.013 \mathrm{~cm}$ ) in acetone for $24 \mathrm{~h}$ followed by brief washing with distilled water. Polysulfone mandrels, $1.27 \mathrm{~cm}$ in length, $0.114 \mathrm{~cm}$ in center diameter, and $0.178 \mathrm{~cm}$ in end diameter, were inserted into the lumen of the tubing. The PEU was stretched to $400 \%$ of original length and tied with 2-0 nonabsorbable silicone-coated sutures on each end.

A pulverized form of PEU, 0.5-1.0-mm particle size, was prepared by cryogenic milling of PEU pellets. To remove antioxidants and other processing aids, compression molded and milled PEU samples were extracted in acetone for $24 \mathrm{~h}$. (It should be noted that acetone extraction is not as efficient as chloroform in removal of processing aids.) PBS was made up of $10 \mathrm{mM}$ potassium phosphate, $10 \mathrm{mM}$ sodium phosphate, and $130 \mathrm{mM} \mathrm{NaCl}, \mathrm{pH}$ 7.2. Hypochlorous acid ( $\mathrm{HOCl}$ ) concentrations were measured as previously described (16). Solutions of $\mathrm{HOCl}$ were prepared immediately before use in $100 \mathrm{mM}$ sodium phosphate buffer (PB), pH 7.2.

Oxidative damage of PEU by PMN. PMN were isolated as described earlier (17) from heparinized venous blood drawn from normal adult donors. The purified PMN ( $>95 \%$ PMN, $>92 \%$ viable by trypan blue exclusion) were diluted in HBSS containing $\mathrm{Ca}^{2+}(1 \mathrm{mM})$ and $\mathrm{Mg}^{2+}(0.5 \mathrm{mM})$. To determine whether contact with PEU surfaces activated the PMN oxidative burst, we used disc-shaped samples cut out of compression-molded PEU. The surface area of these discs was $0.725 \mathrm{~cm}^{2}$, sufficient to cover the bottom of an 8-ml polypropylene scintillation vial. The polymer samples were secured to the bottom of the vials with a layer of Parafilm ${ }^{\oplus}$ (American National Can, Greenwich, CT) between the disk and the vial. A 5-ml suspension of $5 \times 10^{4} /$ $\mathrm{ml}$ PMN in HBSS containing $\mathrm{Ca}^{2+}$ and $\mathrm{Mg}^{2+}$ was spun onto the PEU surface at $250 \mathrm{~g}$ for $10 \mathrm{~min}$. Extent of activation of the surface-associated PMN was assessed using luminol-enhanced $(1 \mu \mathrm{M})$ chemiluminescence in a liquid scintillation counter (model LS 2800; Beckman Instruments, Inc., Fullerton, CA) set in the out-of-coincidence mode.

To assess the effects of PMN on stressed material, segments of PEU $80 \mathrm{~A}$ tubing ( with an inner diameter of $\sim 0.178 \mathrm{~cm}$ and a wall thickness of $\sim 0.013 \mathrm{~cm}$ ) strained to $400 \%$ elongation over a polysulfone mandrel $(1.27 \mathrm{~cm}$ in length, $0.114 \mathrm{~cm}$ in center diameter, and $0.178 \mathrm{~cm}$ in end diameter) were admixed with $\sim 2 \times 10^{6} \mathrm{PMN}$ in $2 \mathrm{ml}$ Hank's buffer containing $\mathrm{Ca}^{2+}$ and $\mathrm{Mg}^{2+}$. Four different sample preparations were included in each of two separate experiments. In some cases, the PMN were allowed to settle onto the PEU surface, and in other cases, the PEU-containing samples were centrifuged for $10 \mathrm{~min}(700 \mathrm{~g})$ after the PMN were added. All samples were incubated for $3 \mathrm{~h}$ at $37^{\circ} \mathrm{C}$, washed/sonicated with $1 \%$ Tween $20(20 \mathrm{~min} / 20 \mathrm{~W})$ and four changes of $\mathrm{dH}_{2} \mathrm{O}(4 \times / 5 \mathrm{~min}$ per $20 \mathrm{~W})$, and dried at room temperature for $2 \mathrm{~d}$. The samples were analyzed by attenuated total reflectance Fourier transform infrared spectroscopy (ATR/FTIR), electron spectroscopic chemical analysis (ESCA), and scanning electron microscopy.

Reaction of $\mathrm{HOCl}$ with PEU. Reactions between $\mathrm{HOCl}$ and PEU powder were monitored by sequential determinations of the amounts of $\mathrm{HOCl}$ remaining during coincubation of the two reactants. Samples containing $400 \mathrm{mg}$ pulverized PEU were incubated in tightly sealed glass vials with $4 \mathrm{ml}$ of $10 \mathrm{mM} \mathrm{HOCl}$ in $\mathrm{PB}$ at $25^{\circ} \mathrm{C}$ with constant mixing. At hourly intervals, residual $\mathrm{HOCl}$ concentrations were measured using an assay for chlorine compounds based on the oxidation of ascorbic acid by $\mathrm{HOCl}(16)$. Additional samples with increasing amounts of PEU powder were similarly incubated for a single time period to determine whether there was a dose-response dependence of $\mathrm{HOCl}$ consumption on the amounts of PEU available for reaction. All incubations were carried out in the dark to avoid photolytic decomposition of chlorine compounds.

Morphology of HOCl-treated PEU. Injection-molded PEU dumbells held at $200 \%$ mechanical strain with Teflon ${ }^{\otimes}$ fixtures were incubated for varying times in a range of $\mathrm{HOCl}$ concentrations. All incuba- tions were carried out on a rotator at $37^{\circ} \mathrm{C}$. After the incubations, the samples were washed with $\mathrm{dH}_{2} \mathrm{O}$ and dried at $55^{\circ} \mathrm{C}$. The morphological characteristics of the samples were assessed through scanning electron microscopy.

$A T R / F T I R$. This infrared spectroscopic technique permits analysis of chemical modifications of polymer surfaces (i.e., $\leq 30 \mu \mathrm{m}$ depth). PEU $80 \mathrm{~A}$ tubing strained to $400 \%$ elongation over a polysulfone mandrel was incubated in PB with or without $10 \mathrm{mM} \mathrm{HOCl}$ on a rotator for $2 \mathrm{~h}$ at $37^{\circ} \mathrm{C}$. The samples were then rinsed thoroughly with $\mathrm{dH}_{2} \mathrm{O}$, dried at $50^{\circ} \mathrm{C}$ for $12 \mathrm{~h}$, and analyzed by ATR/FTIR (model 1720 FTIR; Perkin Elmer Corp., Norwalk, CT). A $45^{\circ} \mathrm{ZnSe}$ crystal was used with a horizontal ATR internal reflection accessory from Spectra-Tech (Stanford, CT).

Gel permeation chromatography. For investigations of possible polymer scission by $\mathrm{HOCl}$, very thin ( $\sim 50 \AA$ thick) films of PEU were prepared to maximize reactions between the polymer and the oxidant. PEU powder was solubilized in 1-methyl-2-pyrrolidone, and these solutions were used to spin coat aluminum wafers. Examination of the surface of these spin-coated wafers by atomic force microscopy indicated ca. $10 \AA$ deviations, suggesting a smooth and uniform layer of PEU. The spin-coated wafers were incubated in $20 \mathrm{ml}$ of $10 \mathrm{mM} \mathrm{HOCl}$ in $100 \mathrm{mM}$ PB or PB alone for $3 \mathrm{~h}$ at $37^{\circ} \mathrm{C}$ on a rotator, washed with $\mathrm{dH}_{2} \mathrm{O}$, and then incubated in $N, N$-dimethylformamide to solvate the polymer.

The solvated polymer then was separated by gel permeation chromatography in order to assess possible changes in molecular weight. Chromatography was performed using a single mixed bed Shodex ${ }^{\star}$ styrene divinyl benzene column $\left(1 \mathrm{ml} / \mathrm{min}, 40^{\circ} \mathrm{C}\right)$ calibrated against polystyrene standards. Eluent was monitored using a refractive index detector (Hewlett Packard, St. Paul, MN).

$E S C A$. In order to monitor possible changes in the elemental composition of oxidized PEU, we carried out ESCA on the surfaces of stressed PEU dumbbells incubated in PB with and without $10 \mathrm{mM}$ $\mathrm{HOCl}$. These samples were incubated for $3 \mathrm{~h}$ with continuous shaking at $37^{\circ} \mathrm{C}$, rinsed with $\mathrm{dH}_{2} \mathrm{O}$, and dried for $20 \mathrm{~h}$ at $50^{\circ} \mathrm{C}$. The center portion of the dumbbells was used for analysis.

In vivo oxidative damage of $P E U$. Implanted samples consisted of ethylene oxide-sterilized PEU tubing (with an inner diameter of $\sim 0.178 \mathrm{~cm}$ and a wall thickness of $\sim 0.013 \mathrm{~cm}$ ) strained to $400 \%$ over four equidistant polysulfone mandrels (total length of strained material $=5.5 \mathrm{~cm}$ ). Ethylene oxide-sterilized control samples showed no signifcant changes by ATR/FTIR and ESCA from nonsterilized control samples, in accord with earlier reports (18).

The animals used for implantation experiments were $150-300 \mathrm{~g}$ male Sprague Dawley rats. Pentobarbital was administered intraperitoneally at a dose of $70 \mathrm{mg} / \mathrm{kg}$ body wt followed ca. $10 \mathrm{~min}$ later by ketamine administered intraperitoneally at a dose of $60 \mathrm{mg} / \mathrm{kg}$ body wt. The strained tubing samples were implanted subcutaneously in the dorsal area, $\sim 1 \mathrm{~cm}$ from and parallel to the midline. The small incision made for this purpose was closed with sutures. After $24 \mathrm{~h}$, the samples were explanted and rinsed in sterile PBS. Half of the samples from each animal were placed in sterile PBS and washed/sonicated with $1 \%$ Tween $20(20 \mathrm{~min} / 20 \mathrm{~W})$ and four changes of $\mathrm{dH}_{2} \mathrm{O}(4 \times / 5$ min per $20 \mathrm{~W}$ ). These samples were then analyzed by ATR/FTIR, ESCA, and SEM. The remaining samples were incubated with $0.5 \mathrm{ml}$ $0.2 \%$ Triton X-100 to release phagocyte granular enzymes. Myeloperoxidase (MPO) activity (as an indicator of numbers of surface-adherent $\mathrm{PMN}$ ) was determined using the $\mathrm{H}_{2} \mathrm{O}_{2}$-dependent reduction of guaiacol (19). Analyses were performed in the presence and absence of $1 \mathrm{mM}$ 3-amino-1,2,4-triazole to distinguish MPO from eosinophil peroxidase $(20,21)$

Reactions of $\mathrm{ONOO}^{-}$with $\mathrm{PEU}$. $\mathrm{ONOO}^{-}$was generated as described earlier (22) via the oxidation of hydroxylamine in an oxygen atmosphere at elevated $\mathrm{pH}$. The concentration of $\mathrm{ONOO}^{-}$was determined using the molar absorptivity of $1,670 \mathrm{M}^{-1} / \mathrm{cm}^{-1}$ at $302 \mathrm{~nm}$ (23). PEU samples strained to $400 \%$ elongation were placed in $10 \mathrm{ml}$ of these solutions, which were sealed and incubated at $25^{\circ} \mathrm{C}$ for $24 \mathrm{~h}$. The initial concentration of $\mathrm{ONOO}^{-}$was $8.8 \mathrm{mM}$ based on the absorbance 
at $302 \mathrm{~nm}$. It should be noted that maintenance of high $\mathrm{pH}$ was necessary because $\mathrm{ONOO}^{-}$is quite short lived at neutral $\mathrm{pH}$ (23).

\section{Results}

Oxidative damage of PEU by PMN. Stressed PEU develops microscopically apparent surface anomalies when implanted for 2 wk in rats (Fig. $1 A$ ). Morphologically similar though not identical lesions appear in material exposed to purified PMN (which, when centrifugally forced to the PEU surface, are activated as measured by luminol-enhanced chemiluminescence [data not shown]) (Fig. $1 B$ ).

Reaction of $\mathrm{HOCl}$ with $\mathrm{PEU}$. Since hydrogen peroxide and superoxide are unable to attack most plastics, we elected to determine whether PEU is damaged by $\mathrm{HOCl}$, the most potent oxidant produced by activated PMN. When samples of pulverized PEU were coincubated with $10^{-2} \mathrm{M} \mathrm{HOCl}$, almost $100 \%$ of added $\mathrm{HOCl}$ was consumed after $5 \mathrm{~h}$ (Fig. $2 A$ ). This reflects PEU-dependent reduction of $\mathrm{HOCl}$ because no decrement in $\mathrm{HOCl}$ was observed in the absence of PEU and the addition of increasing amounts of PEU led to a dose-dependent consumption of $\mathrm{HOCl}$ during $6 \mathrm{~h}$ at $37^{\circ} \mathrm{C}$ (Fig. $2 \mathrm{~B}$ ). It should be noted that, under similar conditions, no consumption of hydrogen peroxide occurred in the presence of added PEU (data not shown). Additionally, as with isolated PMN, SEM demonstrates that surface cracks are generated when PEU is treated with $\mathrm{HOCl}$ (data not shown).

Oxidant-induced changes in polymer composition. PEU exposed to $\mathrm{HOCl}$ has decreased molecular weight compared to control material (Table I). Similar results were reported by Zhao et al. (15) on PEU after 2 wk implantation in rats. The values shown represent weight average molecular weight $(\mathrm{Mw}$, the average molecular size based on the mass fraction) and number average molecular weight $(\mathrm{Mn}$, the "average" chain length in the polymer based on the number fraction). The ratio, $\mathrm{Mw} / \mathrm{Mn}$, is an indication of the breadth of molecular weight distribution. Although the spin-coated wafers were not under applied stress, most of the polymer in this $<10-\mu \mathrm{m}$ thick material was probably available for reaction with solution phase $\mathrm{HOCl}$.

The results of ESCA analysis indicate a $50-100 \%$ increase in the solid phase surface oxygen content of the polymer (Table
II). The surfaces of the HOCl-treated sample, PMN-exposed material and explanted samples all show (somewhat variable) increases in surface oxygen content (and proportionate decrements in both nitrogen and carbon). It should be noted that some of the variation in these values may stem from variable contamination of the surface with an amide extrusion lubricant incorporated into polyurethanes to facilitate manufacturing and processing (18). Although this may complicate the ESCA results shown in Table II, the extent of addition of oxygen to the surface supports some type of polymer oxidation.

An oxidative reaction involving the ether or ester moieties of PEU would be reflected by a decrement in the urethane-aliphatic ester and/or aliphatic ether stretch peaks on ATR/ FTIR analysis. Indeed, a substantial decrement in the aliphatic ether stretch at $1,105-1,110 \mathrm{~cm}^{-1}$ relative to the urethane-aliphatic ester peak at $1,075 \mathrm{~cm}^{-1}$ has been observed in implanted material (7). In fact, the intensity of both aliphatic ether and urethane-aliphatic ester peaks decreases after long-term implantation, suggesting that both groups are oxidatively attacked in vivo. As shown in Fig. 3 B, PEU previously exposed to $\mathrm{HOCl}$ exhibits a decrement in the signal from the urethane-aliphatic ester. Similar changes are seen in material incubated with activated human PMN (Fig. 3 C). Importantly, ATR/FTIR spectra on material implanted for $24 \mathrm{~h}$ exhibit the same decrease in the $1,075 \mathrm{~cm}^{-1}$ urethane-aliphatic ester peak. The IR spectrum of amide wax has no signal in the $1,100-1,075 \mathrm{~cm}^{-1}$ region (18). Therefore, even if the ESCA results are somehow complicated by the presence of an amide wax, this would not affect the results of ATR/FTIR analyses.

However, the selective loss of signal from the urethane-aliphatic ester is not completely consistent with observations on long-term implanted material. In the latter, a decrease in both signals, particularly the aliphatic ether, is seen. Indeed, in our own experiments, material implanted in rats for $2 \mathrm{wk}$ showed substantial decreases in both the $1,075 \mathrm{~cm}^{-1}$ urethane-aliphatic ester peak and the $1,105-1,110 \mathrm{~cm}^{-1}$ aliphatic ether peak (Fig. $3 \mathrm{D}$ ), consonant with destruction of both groups during longterm implantation. These changes in ATR/FTIR are perhaps most easily seen using the peak at $\sim 1,220$ as a reference. The latter has been assigned to the $\mathrm{C}-\mathrm{N}$ stretch and does not appear to be altered by any of the treatments. Because we failed to observe decrements in the aliphatic ether peak after exposure
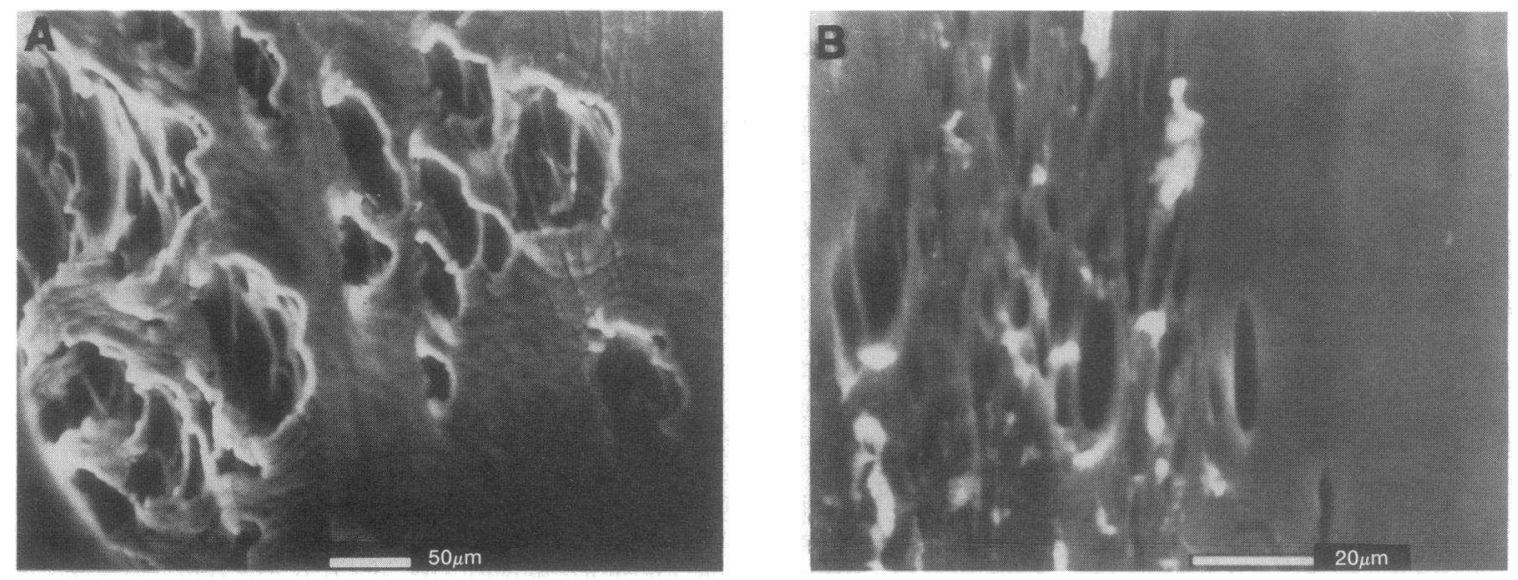

Figure 1. (A) Scanning electron micrograph of PEU 80A, strained to $400 \%$ elongation, implanted for 2 wk subcutaneously in a rat (white bar $=50 \mu \mathrm{m}$ ). (B) PEU 80A strained to $400 \%$ elongation, incubated with human PMN for $3 \mathrm{~h}$ at $37^{\circ} \mathrm{C}$ (white bar $=20 \mu \mathrm{m}$ ). In both cases, the original surface was as smooth as it is on the far right of $B$. 

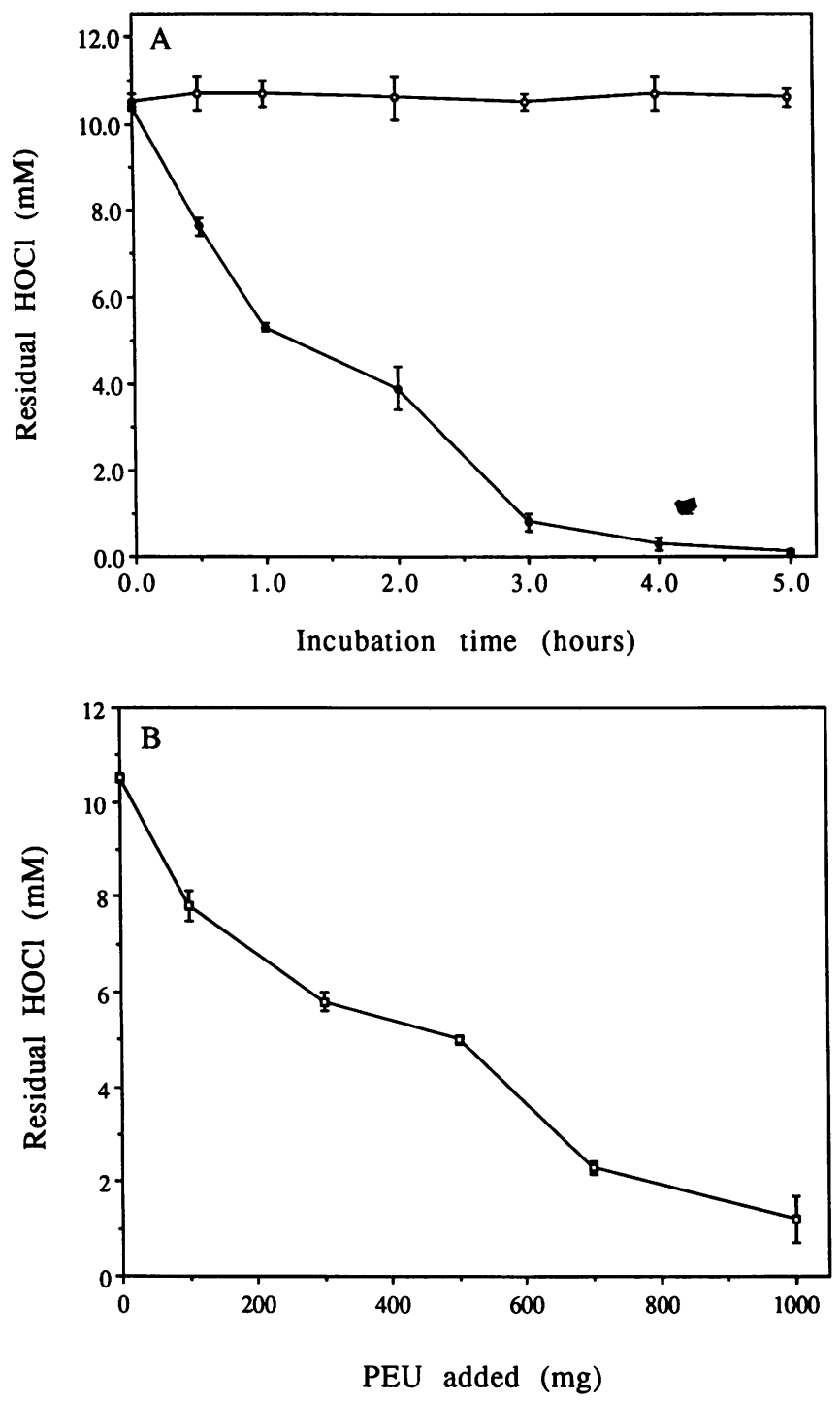

Figure 2. (A) Consumption of $\mathrm{HOCl}$ during incubations with (solid symbols) and without (open symbols) PEU at $25^{\circ} \mathrm{C}$. Incubation mixtures contained $4 \mathrm{ml} 10 \mathrm{mM} \mathrm{HOCl}+400 \mathrm{mg}$ PEU powder, and control samples contained $4 \mathrm{ml} 10 \mathrm{mM} \mathrm{HOCl}$ alone. These results are representative of three separate experiments. Vertical bars denote \pm 1 SD of triplicate determinations from a single experiment. $(B)$ Dose-dependent consumption of $\mathrm{HOCl}$ during $2 \mathrm{~h}$ incubations with increasing amounts of PEU at $37^{\circ} \mathrm{C}$. Incubation mixtures contained $4 \mathrm{ml} 10 \mathrm{mM} \mathrm{HOCl}+$ PEU powder. These results are representative of two separate experiments. Vertical bars denote \pm 1 SD of triplicate determinations from a single experiment.

to $\mathrm{HOCl}$, we suspected that in vivo attack on the aliphatic ether might be caused by another type of phagocyte-generated oxidant. Therefore, we carried out limited investigations of peroxynitrite $\left(\mathrm{ONOO}^{-}\right)$, an extremely potent oxidant (24) that may be the predominant form of $\mathrm{NO}^{\circ}$ produced by macrophages (25).

Preliminary assessment of possible reactions involving $\mathrm{ONOO}^{-}$was performed by incubating PEU tubing in solutions containing $\mathrm{ONOO}^{-}$as described in the Methods. Although $\mathrm{ONOO}^{-}$is highly reactive and, therefore, ephemeral, we elected to incubate all samples with the $\mathrm{ONOO}^{-}$containing solutions for $24 \mathrm{~h}$ to ensure complete reaction. The $\mathrm{ONOO}^{-}$-
Table I. Gel Permeation Chromatographic Analysis of Control, HOCl-treated (10 mM for $3 \mathrm{~h}$ ) and Implanted PEU samples*

\begin{tabular}{llll}
\hline \multicolumn{1}{c}{ Sample } & Mw & Mn & Mw/Mn \\
\hline PEU “wafers" & & & \\
$\quad$ in vitro: & & & \\
Control & 293,624 & 244,645 & 1.2 \\
+HOCl & 130,900 & 99,486 & 1.3 \\
& $(55 \%$ decrease $)$ & $(60 \%$ decrease $)$ & \\
Implanted PEU & & & \\
Control & 263,000 & 102,000 & 2.6 \\
Implanted & 139,000 & 40,000 & 3.5 \\
& $(47 \%$ decrease $)$ & $(61 \%$ decrease $)$ & \\
\hline
\end{tabular}

* Values shown represent single determinations of $\mathrm{Mw}$ and $\mathrm{Mn}$ molecular weights. ${ }^{\ddagger}$ Incubated with $10 \mathrm{mM} \mathrm{HOCl}$ for $3 \mathrm{~h}$ at $37^{\circ} \mathrm{C}$. ${ }^{\S}$ Material implanted 2 wk in rats. Data from Zhao et al. (15).

treated PEU samples exhibited a decrease in the $1,105-1,110$ $\mathrm{cm}^{-1}$ aliphatic ether peak relative to the $1,075 \mathrm{~cm}^{-1}$ urethanealiphatic ester peak (Fig. 4). Limited elemental analysis of the $\mathrm{ONOO}^{-}$-exposed material showed a substantial increase in surface oxygen content (Table III).

Thus, ATR/FTIR results on implanted PEU 80A support the idea that, in vivo, there is an early attack on the urethanealiphatic ester linkage, probably by PMN-derived HOCl. However, after implantation for 1 and 2 wk, the attack appears predominantly on the aliphatic ether linkages, as is typical of in vivo stress-cracked PEU insulation.

Finally, if PMN-mediated oxidant damage is an important mechanism of early oxidant destruction of implanted PEU, it is necessary that these cells be present in suitable numbers and at appropriate times to cause such damage. Therefore, we estimated the numbers of PMN attracted to the surfaces of PEU implants by measuring the MPO activity on the surface of implanted material. As shown in Table IV, relatively large numbers of PMN are present on the implant surface at times $\leq 24 \mathrm{~h}$

Table II. Electron Spectroscopic Chemical Analysis of Control, HOCl-treated, PMN-exposed, and Explanted PEU Surfaces*

\begin{tabular}{lccc}
\hline PEU sample & Oxygen (\%) & Nitrogen (\%) & Carbon (\%) \\
\hline Control & & & \\
Run 1 & 8.16 & 2.89 & 88.96 \\
Run 2 & 6.53 & 2.64 & 90.83 \\
HOCl-treated & & & \\
Run 1 & 12.48 & 2.54 & 84.98 \\
Run 2 & 10.50 & 2.67 & 86.84 \\
PMN-treated & & & \\
Run 1 & 17.63 & 2.55 & 79.83 \\
Run 2 & 10.90 & 2.72 & 86.38 \\
24-hr explant & & & \\
Run 1 & 14.88 & 3.48 & 81.65 \\
Run 2 & 17.65 & 3.60 & 78.75 \\
& & & \\
\hline
\end{tabular}

* Values represent elemental composition of the PEU surface to a depth of $10-20 \AA$. 

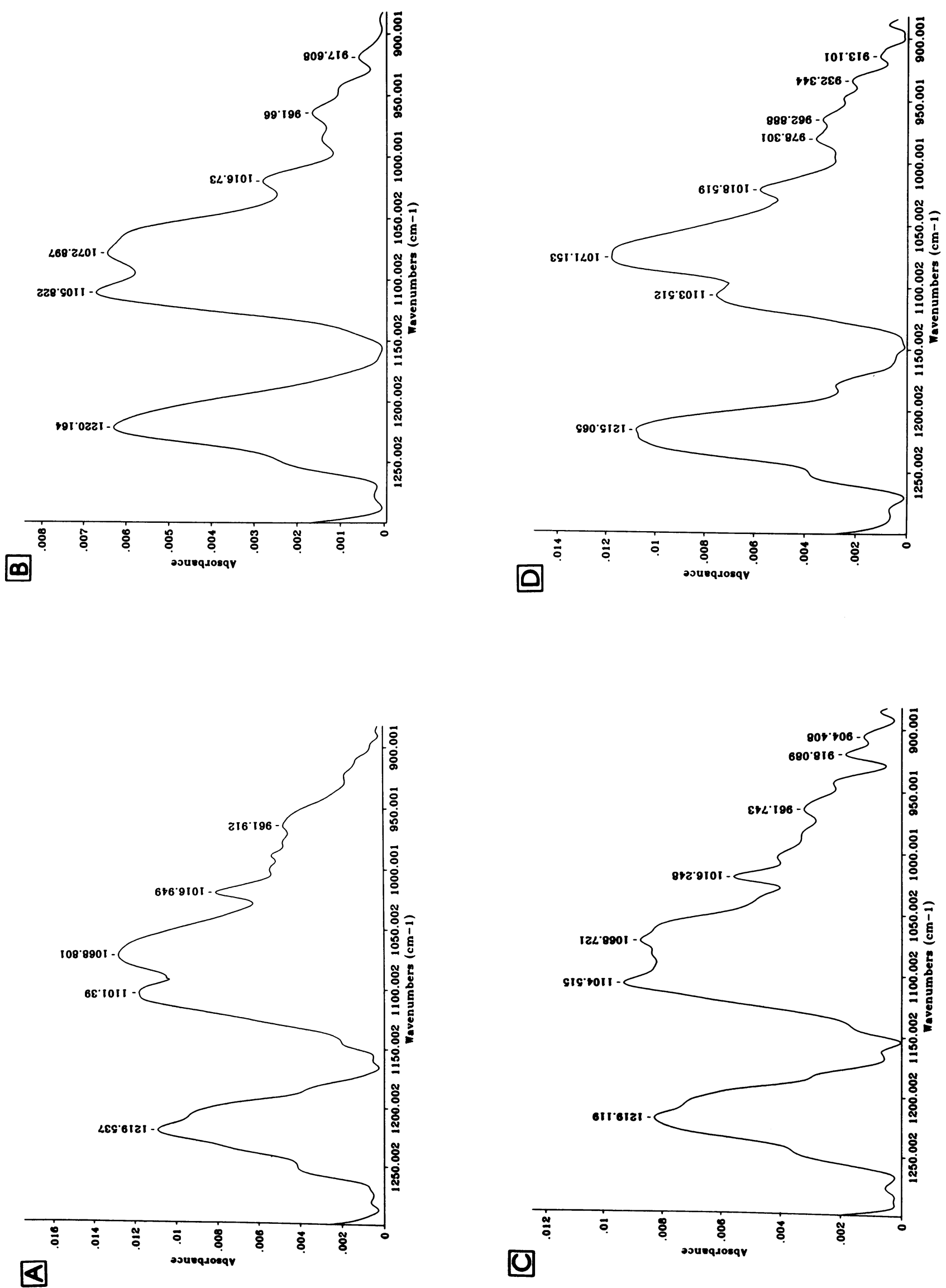

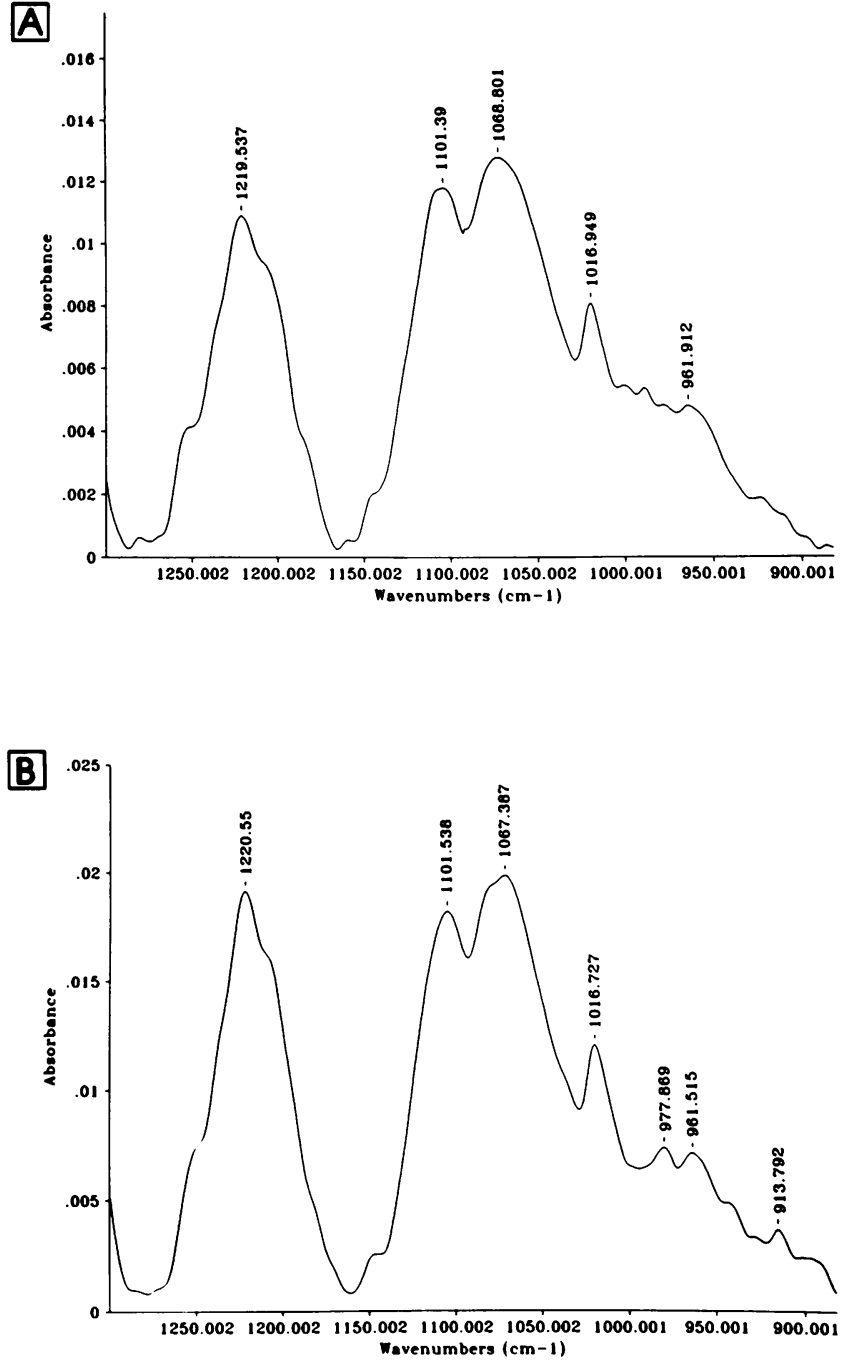

Figure 4. ATR/FTIR spectrum PEU tubing strained to $400 \%$ elongation before $(A)$ and after $(B)$ incubation for $24 \mathrm{~h}$ at $25^{\circ} \mathrm{C}$ in $10 \mathrm{ml}$ of $8.8 \mathrm{mM} \mathrm{ONOO}^{-}$(nominal initial concentration). Note the moderate decrease in peak height at $\sim 1,100$ vs peak at $\sim 1,220$.

after implantation. The eventual disappearance of PMN would be expected because, as has been described by others $(13,14$, 26 ), this is a typical acute inflammatory response. As is evident from the minimal inhibition of peroxidase activity by 3-amino1,2,4-triazole (which preferentially inhibits eosinophil peroxidase), almost all the implant-associated cells appear to be MPO-bearing PMN. Microscopic analysis of some of these implants affirmed the presence of PMN and monocytic cells at 24 $h$, with only rare eosinophils.
Table III. Electron Spectroscopic Chemical Analysis of Control PEU and PEU Exposed to ONOO- for $24 \mathrm{~h}$ at $25^{\circ} \mathrm{C}^{*}$

\begin{tabular}{lrr}
\hline & Control & ONOO $^{-}$ \\
\hline Oxygen (\%) & 7.76 & 18.57 \\
Carbon (\%) & 88.81 & 77.66 \\
Nitrogen (\%) & 3.43 & 3.77 \\
\hline
\end{tabular}

* Results represent values obtained from single samples.

\section{Discussion}

The increasing use of implantable biomaterials has brought additional awareness of the importance and complexity of reactions to foreign bodies. In many cases, the presence of an implant results in undesirable host responses that can be damaging to both the recipient and the device itself, as is evident in the stress cracking of some types of PEU. Polyetherurethanes have played an important role in the development of many types of implantable devices, such as circulatory assist devices, pulse generator connectors, and vascular catheters. However, some types of PEU are subject to degradation in the body, a process that has been termed environmental stress cracking. Stress cracking is thought to require mechanical or endogenous stress on the material and contact with adherent phagocytic cells ( 7 , 15). Therefore, the mechanisms whereby phagocytic cells might degrade a material as chemically stable as PEU are of some interest.

Phagocytes have a diverse armamentarium for combating invading microbes including oxygen-independent and oxygendependent killing mechanisms. As might be expected, plastic polymers resist degradation by oxygen-independent mechanisms (7). On the other hand, oxidants produced by phagocytes potentially are capable of reacting with a wide range of molecules. Hydrogen peroxide has been previously shown, in the absence of metals, not to cause PEU degradation (7). However, PMN ordinarily convert substantial amounts of hydrogen peroxide to the more potent oxidant, $\mathrm{HOCl}$, through the action of MPO (27). Hypochlorous acid is one of the most reactive oxidants produced by $\mathrm{PMN}$, and we hypothesized that $\mathrm{HOCl}$ was a likely cause of in vivo degradation of plastic polymers.

In partial support of this idea, we find that during incubations of PEU with $\mathrm{HOCl}$, there is a net consumption of $\mathrm{HOCl}$. The disappearance of $\mathrm{HOCl}$ clearly involves reaction with the PEU and the addition of increasing amounts of the polymer results in the consumption of greater amounts of $\mathrm{HOCl}$. Furthermore, PEU incubated with $\mathrm{HOCl}$ develops lesions analogous to those displayed by authentic in vivo stress cracked implants. The concentrations of reagent $\mathrm{HOCl}$ used in the present

Figure 3. (A) ATR/FTIR spectrum of control PEU 80A strained to $400 \%$ elongation and incubated in HBSS for $3 \mathrm{~h}$ with continuous shaking at $37^{\circ} \mathrm{C}$. (B) ATR/FTIR spectrum of PEU 80A strained to $400 \%$ elongation and incubated in $10 \mathrm{mM} \mathrm{HOCl}$ for $2 \mathrm{~h}$ with continuous shaking at $37^{\circ} \mathrm{C}$. Note diminution in the height of the urethane-aliphatic ester peak at $\sim 1,070$. (C) ATR/FTIR spectrum of PEU 80A strained to 400\% elongation, incubated with purified human PMN that were centrifugally forced to the PEU surface (without further stimulation of the PMN) for $3 \mathrm{~h}$ at $37^{\circ} \mathrm{C}$. Note similar diminution of the urethane-aliphatic ester peak at $\sim 1,070$. (D) ATR/FTIR spectrum of PEU 80A strained to $400 \%$ elongation, implanted subcutaneously for $2 \mathrm{wk}$ in rats. Note the substantial reduction in height of the peak at $\sim 1,100$. The results shown are representative of those obtained from duplicate experiments in all cases. 
Table IV. Peroxidase Activity on the Surface of PEU Samples (Surface Area $=2.1 \mathrm{~cm}^{2}$ ) Implanted Subcutaneously in Rats for $24 h$ and $2 w k$

\begin{tabular}{lcc}
\hline & $\begin{array}{c}\text { Surface peroxidase } \\
\text { activity* }\end{array}$ & Calculated PMN $/ \mathrm{cm}^{24}$ \\
\hline 24-hour implant & $\begin{array}{c}7.03 \\
( \pm 0.02)\end{array}$ & $3.04 \times 10^{5}$ \\
2-wk implant & $\begin{array}{c}5.082 \\
( \pm 0.03)\end{array}$ & $3.57 \times 10^{3}$ \\
& & \\
\hline
\end{tabular}

* The results are expressed as $\mathrm{mU} / \mathrm{cm}^{2}$. Assays carried out in the presence of $1 \mathrm{mM} 3$-amino-1,2,4-triazole indicate that $<10 \%$ of surface peroxidase activity is caused by eosinophil peroxidase. ${ }^{\ddagger} \mathrm{Calcu}-$ lated on the basis of an independently measured value for murine PMN MPO activity of $23 \mathrm{nU} /$ cell.

experiments ( $10 \mathrm{mM})$ may appear high. However, given the amounts of $\mathrm{HOCl}$ that may be produced by activated human PMN (1-200 nM $/ 10^{6}$ cells per $2 \mathrm{~h}$; references 16,27$)$, and the number of PMN found on surfaces of short-term implants $\left(>10^{5} / \mathrm{cm}^{2} ;\right.$ reference 14$)$, it is quite possible that surface concentrations of $\mathrm{HOCl}$ may approach $10 \mathrm{mM}$ in vivo. Nonetheless, it should be emphasized that, morphologically, the abnormalities found in material exposed to reagent $\mathrm{HOCl}$ are not identical to those observed in in vivo stress-cracked material (perhaps implying the occurrence in vivo of unknown secondary degradation events).

Consideration of the structure of PEU 80A 2363 (Fig. 5 A) suggested that the urethane-aliphatic ester and aliphatic ether groups might be most susceptible to oxidative attack. In partial support of this supposition, it had been observed earlier that polyurethanes with lower ether contents are less susceptible to stress cracking (28). Although the reactions involved are not precisely known, it is possible that oxidation of the aliphatic ether by peroxynitrite may involve hydrogen abstraction followed by oxygen addition to the resultant carbon-centered radical and ultimate scission of the polymer (Fig. $5 \mathrm{~B}$ ). On the other hand, hypochlorous acid may react with the urethane-aliphatic ester via a nucleophilic attack on the carbon of the $\mathrm{C}=\mathrm{O}$ with a concomitant two-electron oxidation of the alcohol to an aldehyde (Fig. $5 C$ ).

Regardless of the precise mechanisms, both models predict $(a)$ scission of the polymer; $(b)$ an increment in surface oxygen content; and $(c)$ reaction (i.e., disappearance on ATR/FTIR) of the aliphatic ether and/or the urethane-aliphatic ester peaks. If so, it would be predicted that (1) the ether stretch peaks on ATR/FTIR would diminish, (2) scission of the surface polymer would lead to a decrease in average molecular weight, and (3) the surface composition of the polymer would change, showing an increase in oxygen.

Indeed: ( $a$ ) ATR/FTIR analysis of HOCl-treated PEU reveals that the ether linkages are being attacked. Similar changes occurred in PEU exposed to purified human PMN and also have been observed in in vivo environmental stress-cracked PEU (18). (b) Chromatographic analyses demonstrate that $\mathrm{HOCl}$ treatment of PEU causes a decrease in average polymer molecular weight similar to that found in an earlier in vivo implantation study (15). (c) Finally, there are substantial increases in surface oxygen concentration of PEU-treated with $\mathrm{HOCl}$ and in material incubated with human PMN. Overall, these results provide strong support for the idea that PMN-derived $\mathrm{HOCl}$ may be a major early contributor to in vivo PEU stress cracking.

However, the ATR/FTIR changes produced by exposure of material to reagent $\mathrm{HOCl}$ are not precisely those seen in long-term implants. HOCl-treated PEU exhibits a reduction in the urethane-aliphatic ester stretch relative to the aliphatic ether stretch peaks, whereas authentic stress-cracked material shows reduction in both, particularly the aliphatic ether stretch. This suggests that other potent oxidants, possibly $\mathrm{ONOO}^{-}$produced by macrophages (24), might be involved. Such secondary oxidant attack would also conform to the succession of inflammatory cell types typical of acute vs chronic inflammatory responses (wherein PMN may predominate for 1-2 d, but are supplanted by macrophages that may persist for months or years around implants $)(13,14,29)$. Indeed, treat-

$\mathbf{A}$

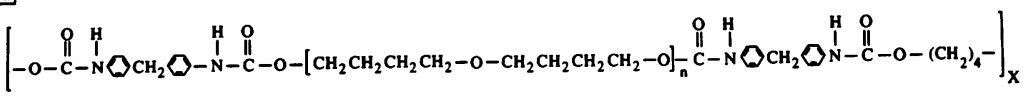

回
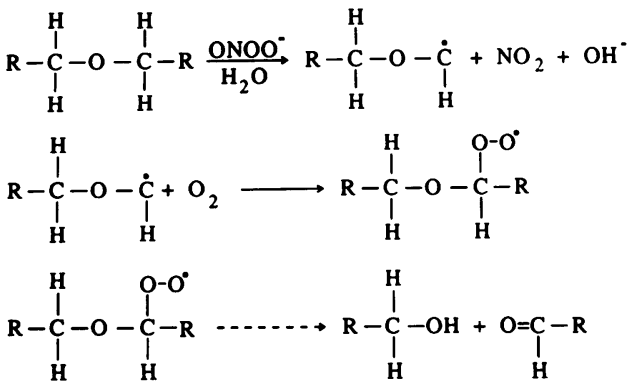

C<smiles>[R]C(=O)OC([R])[Ge]Cl</smiles>

Figure 5. (A) Structure of polyetherurethane "Pellethane" 2363 80A. (B) Hypothesized mode of oxidation of the aliphatic ether bridge of PEU by $\mathrm{ONOO}^{-}$. The third reaction in this sequence (dashed line) probably involves several steps. $(C)$ Hypothesized mode of oxidation of the urethane-aliphatic ester bridge by $\mathrm{HOCl}$. Note that both reactions should cause scission of the polymer and increments in surface oxygen content. 
ment of PEU with $\mathrm{ONOO}^{-}$causes a selective reduction in the aliphatic ether stretch at $1,110 \mathrm{~cm}^{-1}$. This is typical of changes seen in long-term implants, wherein both aliphatic ether and urethane-aliphatic ester peaks are diminished. The probable involvement of $\mathrm{PMN}$-derived $\mathrm{HOCl}$ and macrophage-derived $\mathrm{NO}^{\circ} / \mathrm{ONOO}^{-}$in the in vivo degradation of PEU is reinforced by analyses of the elemental composition of the uppermost 10-20 $\AA$ of the material. Surface oxygen concentration is approximately doubled in PEU treated with reagent $\mathrm{HOCl}$ or $\mathrm{ONOO}^{-}$and in PEU exposed to isolated PMN in vitro. This oxygenation of the surface resembles that observed in both short- and long-term in vivo PEU implants.

Some of our in vivo work also supports the idea that PMN may be involved in an initial attack on PEU urethane-aliphatic ester linkages, whereas later oxidative attack may derive from $\mathrm{ONOO}^{-}$produced by PMN or macrophages. After $24 \mathrm{~h}$ implantation, PEU shows a decrease in the $1,075 \mathrm{~cm}^{-1}$ urethanealiphatic ester stretch relative to the $1,110 \mathrm{~cm}^{-1}$ aliphatic ether stretch. However, after 1 and 2 wk, there is substantial reduction of the aliphatic ether linkages, a change also seen on exposure of PEU to reagent $\mathrm{ONOO}^{-}$.

Thus, it appears that PEU implants may be subject to sequential attack by $\mathrm{PMN}$-derived $\mathrm{HOCl}$, and $\mathrm{NO}^{\circ}$ and $\mathrm{ONOO}^{-}$, which may be produced by macrophages. The relative importance of these two types of oxidant in vivo remains to be determined. However, it is likely that $\mathrm{HOCl}$ attack within the first few hours of implantation may set up the material for continuous degradation by oxidants of macrophage origin.

Chemically stable foreign matter may remain in somatic tissues for years without any serious effects. Nonetheless, stable foreign material can elicit a dynamic, long-term inflammatory response that generally involves long-lived foreign body giant cells. The implantation of theoretically stable polymers is often followed by chronic inflammation that may even damage the polymer itself. The stability of implanted biomaterials can only be predicted if the interactions between inflammatory cells and the biomaterials are known. Once these mechanisms are understood, it may be possible to produce materials that trigger minimal inflammation or materials that are sufficiently durable to withstand the hostile responses of the host.

\section{Acknowledgments}

We thank Steve Skorich, Jerry Dzik, Chris Hobot, Vern Iverson, Raul Carretta, Larry Zazerra, and Terry Stange for their generous help with various aspects of this work and Diane Konzen for expert manuscript preparation. We also acknowledge valuable discussions with Professors Willem Koppenol, Maurice Kreevoy, and Arne Slungaard.

This work was partially supported by a grant-in-aid from Medtronic Corp.

\section{References}

1. Thoma, R. J., and R. E. Phillips. 1987. Studies of poly(ether)urethane pacemaker lead insulation oxidation. J. Biomed. Mater. Res. 21:525-530.

2. Boretos, J. W., and W. S. Pierce. 1967. Segmented polyurethane: A new elastomer for biomedical applications. Science (Wash. DC). 158:1481-1482.

3. Boretos, J. W., W. S. Pierce, R. E. Baier, A. F. Leroy, and H. J. Donachy.
1975. Surface and bulk characteristics of a polyether urethane for artificial hearts. J. Biomed. Mater. Res. 9:327-340.

4. Boretos, J. W., D. E. Detmer, and J. H. Donachy. 1971. Segmented polyurethanes: a polyether polymer. II. Two years' experience. J. Biomed. Mater. Res. 5:373-387.

5. Boretos, J. W. 1972. Tissue pathology and physical stability of a polyether elastomer on three-year implantation. J. Biomed. Mater. Res. 6:473-476.

6. Phillips, R. E., M. C. Smith, and R. J. Thoma. 1988. Biomedical applications of polyurethanes: implications of failure mechanisms. J. Biomater. Appl. 3:207-227.

7. Stokes, K. B. 1988. Polyether polyurethanes: biostable or not? J. Biomater. Appl. 3:228-259.

8. Coury, A. J., P. C. Slaikeu, P. T. Cahalan, K. B. Stokes, and C. M. Hobot. 1987. Factors and interactions affecting the performance of polyurethane elastomers in medical devices. Symposium on Biocompatibility of Polyurethanes. Newark, NJ.

9. Coury, A. J., K. B. Stokes, P. T. Cahalan, and P. C. Slaikeu. 1987. Biostability considerations for implantable polyurethanes. Life Support Syst. 5:25-39.

10. Stokes, K., and K. Cobian. 1982. Polyether polyurethanes for implantable pacemaker leads. Biomaterials. 3:225-231.

11. Stokes, K. B., A. W. Frazer, and E. A. Carter. 1987. The biostability of various polyether polyurethanes under stress. In Advances in Biomaterials. S. M. Lee, editor. Technomic Publishing Company, Inc., Lancaster, PA. pp. 235-244.

12. Engel, L., H. Klingele, G. W. Ehrenstein, and H. Schaper. 1981. An Atlas of Polymer Damage. Prentice-Hall, Inc., Englewood Cliffs, NJ. p. 227.

13. Marchant, R. E., K. M. Miller, and J. M. Anderson. 1984. In vivo biocompatibility studies. V. In vivo leukocyte interactions with biomer. J. Biomed. Mater. Res. 18:1169-90.

14. Tang, L., A. H. Lucas, and J. W. Eaton. 1993. Inflammatory responses to implanted polymeric biomaterials: role of surface adsorbed IgG. J. Lab. Clin. Med. In press.

15. Zhao, Q., M. P. Agger, M. Fitzpatrick, J. M. Anderson, A. Hiltner, K. Stokes, and P. Urbanski. 1990. Cellular interactions with biomaterials: in vivo cracking of pre-stressed Pellethane 2363-80A. J. Biomed. Mater. Res. 24:621637.

16. Chesney, J. A., J. R. Mahoney Jr., and J. W. Eaton. 1991. A spectrophotometric assay for chlorine-containing compounds. Anal. Biochem. 196:262-266.

17. Hamers, M. N., A. A. M. Bot, R. S. Weening, H. J. Sips, and D. Roos 1984. Kinetics and mechanism of the bactericidal action of human neutrophils against Escherichia coli. Blood. 64:635-641.

18. Coury, A. J., P. C. Slaikeu, P. T. Cahalan, K. B. Stokes, and C. M. Hobot. 1988. Factors and interactions affecting the performance of polyurethane elastomers in medical devices. J. Biomater. Appl. 3:130-179.

19. Himmelhoch, S. R., W. H. Evans, M. G. Mage, and E. A. Peterson. 1969. Purification of myeloperoxidases from the bone marrow of the guinea pig. Biochemistry. 8:914-921.

20. Cramer, R., M. R. Soranzo, P. Dri, R. Menegazzi, A. Pitotti, G. Zabucchi, and P. Patriarea. 1984. A simple reliable assay for myeloperoxidase activity in mixed neutrophil-eosinophil cell suspensions: application to detection of myeloperoxidase deficiency. J. Immunol. Methods. 70:119-125.

21. Thomas, E. L., and M. Fishman. 1986. Oxidation of chloride and thiocyanate by isolated leukocytes. J. Biol. Chem. 261:9694-9702.

22. Hughes, M. N., and H. G. Nicklin. 1970. The chemistry of peroxonitrites. II. Cu(II)-catalyzed reaction between hydroxylamine and peroxonitrite in alkali. J. Chem. Soc. (A), 925-928.

23. Benton, D. J., and P. Moore. 1970. Kinetics and mechanism of the formation and decay of peroxynitrous acid in perchloric acid solutions. J. Chem. Soc. (A), 3179-3182.

24. Koppenol, W. H., J. J. Moreno, W. A. Pryor, H. Ischiropoulos and J. S. Beckman. 1992. Peroxynitrite, a cloaked oxidant formed by nitric oxide and superoxide. Chem. Res. Toxicol. 5:834-842.

25. Ischiropoulos, H., L. Zhu, and J. S. Beckman. 1992. Peroxynitrite formation from macrophage-derived nitric oxide. Arch. Biochem. Biophys. 298:446451.

26. Cotran, R. S., V. Kumar, and S. L. Robbins. 1989. Pathologic Basis of Disease. 4th Edition. W. B. Saunders Company. PA.

27. Weiss, S. J. 1989. Tissue destruction by neutrophils. N. Engl. J. Med. 320:365-376.

28. Coury, A. J., P. C. Slaikeu, P. T. Cahalan, and K. B. Stokes. 1987. Medical applications of implantable polyurethanes: current issues. In Progress in Rubber and Plastics Technology. Vol. 3, no. 4, pp. 24-37.

29. Ziats, N. P., K. M. Miller, and J. M. Anderson. 1988. In vitro and in vivo interactions of cells with biomaterials. Biomaterials. 9:5-13. 